\title{
Congenital deficiency of alpha feto-protein
}

\author{
Reuven Sharony ${ }^{1}$, Idit Zadik ${ }^{2}$ and Ruti Parvari ${ }^{*, 2}$
}

\author{
${ }^{1}$ The Genetic Institute, Sapir Medical Center - Meir Hospital, Kfar Saba 44281, Israel (affiliated with Sackler School of \\ Medicine, Tel Aviv University, Tel Aviv, Israel); ${ }^{2}$ The Department of Molecular Developmental Genetics, The Health \\ Science Faculty, Ben Gurion University of the Negev, Beer Sheba 84105, Israel
}

\begin{abstract}
Alpha-fetoprotein (AFP) is the main fetus serum glycoprotein with a very low concentration in the adult. AFP deficiency is a rare phenomenon. We studied two families with congenital AFP deficiency and searched for mutations in the AFP gene. We identified one mutation of 2 base deletion in exon 8 , in both families, that leads to the congenital deficiency of AFP. The mutation nt930-931delCT (T294fs25X) creates a frameshift after codon 294 that leads to a stop codon after 24 amino acids, thus truncating the normal length of AFP of 609 amino acids. All the affected children were found to be homozygous for the mutation as was one of the fathers. The affected individuals were asymptomatic and presented normal development. This first identification of a mutation in the AFP gene demonstrates for the first time that deficiency of AFP is compatible with human normal fetal development and further reproduction in males. European Journal of Human Genetics (2004) 12, 871-874. doi:10.1038/sj.ejhg.5201246
\end{abstract}

Published online 28 July 2004

Keywords: deficiency of Alpha-fetoprotein; frameshift mutation; normal development

\section{Introduction}

Alpha feto-protein (AFP) was identified in human fetuses in 1956 by Bergstrand and Czar. ${ }^{1}$ Since the protein produced by the embryo at high levels is transferred to the maternal blood circulation, it is widely used in the clinic in order to detect fetal anomalies. Abnormal levels of embryonic AFP in the maternal serum are indicative of spina bifida or Down's syndrome in the fetus. ${ }^{2-4}$ It is also clinically used to monitor certain types of cancer. ${ }^{5}$

The synthesis of AFP decreases dramatically after birth, and only trace amounts are detected in the adult. ${ }^{6}$ However, a condition in which persistent high levels of AFP are found was reported for at least 10 cases (eg McVey et $a l^{7}$ Blesa et $a l,{ }^{8}$ and Alj et al, ${ }^{9}$ OMIM \#104150) and recently two mutations causing this condition were identified as alterations in hepatocyte nuclear factor-1binding sites in the AFP promoter. ${ }^{9}$ Nevertheless, only one report described two normal fetuses with undetected levels of $\mathrm{AFP}^{10}$ and lately we described two cases in two unrelated

${ }^{*}$ Correspondence: Dr R Parvari, Tel: +972 8 6479972; Fax: +972 8 6276215; E-mail: ruthi@bgumail.bgu.ac.il

Received 2 March 2004; revised 29 April 2004; accepted 12 May 2004
Arab families. ${ }^{11}$ The molecular explanation for the pathophysiology of such situation was not provided. Here we report the molecular basis of this condition for the Arab families.

\section{Subjects and methods}

The study was approved by the Sapir Medical Center review board. The pedigrees of the two families are presented in Figure 1 . The medical history is detailed, ${ }^{11}$ accordingly: patients V3, V5 (reported to be deficient of AFP by the mother ${ }^{11}$ but not verified) and V6 (case no. 2, patient $\mathrm{BJ}^{11}$ ) of family A and IV6 of family B (case no. 1, patient $\mathrm{RM}^{11}$ ) were defined as lacking normal amounts of AFP as fetuses. The amniotic AFP level of patient IV6 of family B was tested by radioimmunoassay using monoclonal antibodies and the electroimmunodiffusion (Rocket) method. ${ }^{11}$ The sera of the mothers of the patients' detailed, during pregnancy, and the sera post delivery of the patients, were tested using the radioimmunoassay method. ${ }^{11}$ The other members of the family were not tested. Immunohistochemical staining of AFP performed on the placenta of patient IV6 of family B revealed multifocal positivity on both the maternal and 


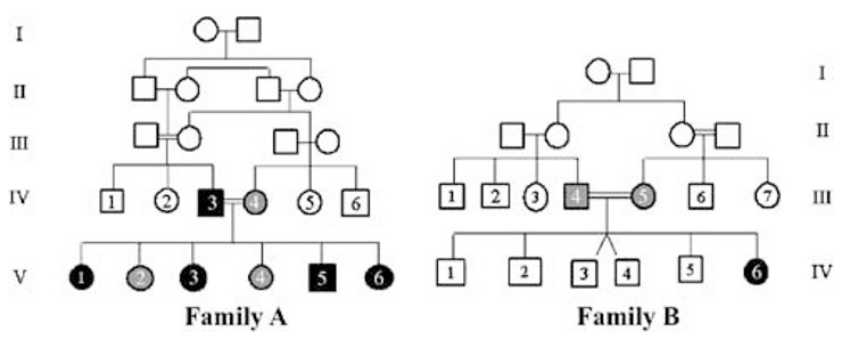

Figure 1 Pedigrees of the two Arab families with the fetuses showing congenital absence of AFP. Patients V3, V5, and V6 of family A and IV 6 of family B were defined as lacking normal amounts of AFP as fetuses. ${ }^{11}$ Individuals homozygous for the mutation appear in black and heterozygous in gray. The definition was done by the result of the restriction analysis, see Figure 3 .

fetal sides, whereas for the placenta of patient V6 of family A multifocal positivity was detected only on the fetal side. ${ }^{11}$ The labor of patient IV6 of family B was induced at 34 weeks due to mild pre-eclampsia, the newborn weighed $1740 \mathrm{~g}$ and was normal. ${ }^{11}$ Its placenta presented inflammatory sites and cellular infiltrates. ${ }^{11}$ Patient V6 of family A was born by normal vaginal delivery and was normal; however, signs of placenta inflammation in the placental membranes were noted and monosomy 16 was found in placenta cells of both patients described. ${ }^{11}$

DNA was prepared from peripheral lymphocytes of all individuals of the fifth generation of family $\mathrm{A}$ and their parents and individual IV6 and his parents of family B. Primers were designed to enable PCR amplification of the 14 exons of the Afp gene encoding the coding region and their borders. The PCR amplification of exon 8 was done with primers: F: $5^{\prime}$ TCCTTCTTTCCTGGCCTTTT $3^{\prime}$, R: $5^{\prime}$ GCTCAGAACATTCTAGCCAAA $3^{\prime}, 30$ cycles of $94^{\circ} 1^{\prime}, 59^{\circ}$ $1^{\prime}$, and $72^{\circ} 1^{\prime}$. The PCR product of five separate reactions was purified using the Quiaquick PCR purification kit (Quiagen, Germany) and directly sequenced using an AB373 apparatus. Restriction analysis with Psy1 (NEB, MA, USA) was performed on PCR products of the family members according to the manufacturer's recommendations.

\section{Results}

To verify the molecular cause of the AFP absence, we analyzed the sequence of all the exons of the Afp and their borders in patient $\mathrm{V} 6$ of family A. We identified a deletion of two nucleotides at positions 930-931 of the mRNA (Acc. No. NM_001134) in exon 8 (nt 930-931delCT, Figure 2) that results in frameshift: the last relevant amino acid is threonine at position 294, followed by 24 irrelevant amino acids and a stop codon (T294fs25X). The protein is thus truncated to 318 amino acids, instead of the normal length of 609 amino acids. This deletion creates a novel restriction site for the enzyme Psy1 that was used to analyze the parents and all siblings of family $\mathrm{A}$ and the patient of family B and his parents (Figure 3). This analysis shows that the same mutation in homozygosity causes the AFP absence in family B that is of the same Arab origin (though the families do not know to be related). The father of family A is homozygous for the mutation; accordingly, his children are either homozygous or heterozygous for the mutation.

\section{Discussion}

We present a homozygous deletion of two nucleotides in exon 8 of the AFP gene, causing a frameshift that starts after codon 194 and create stop codon after 24 amino acids
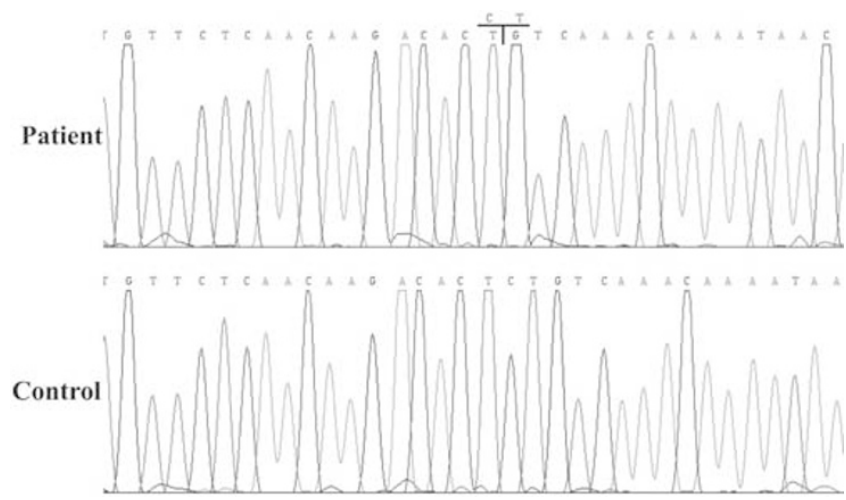

Figure 2 Sequence of exon 8 showing the deletion of the CT bases in positions 930-931 of the mRNA (Acc. No. NM_001134) in patient V6 of family A.

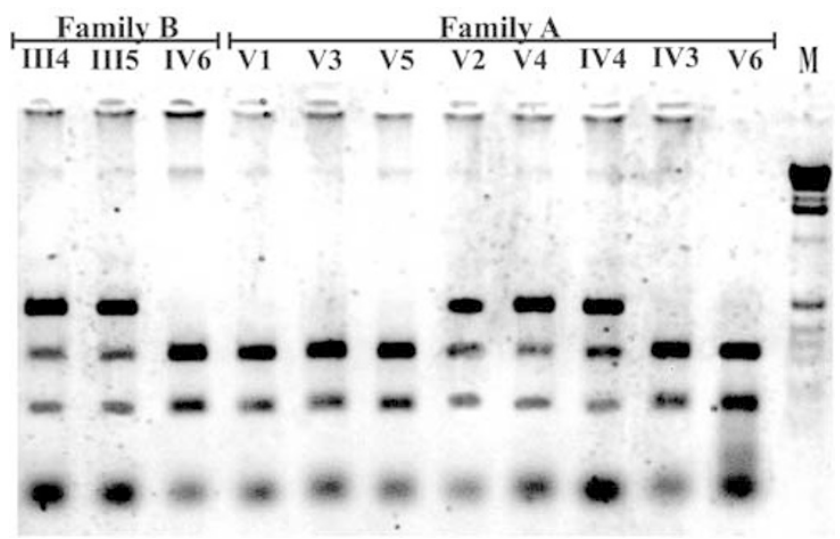

Figure 3 Restriction analysis with the enzyme Psy1: The 2 base deletion creates a novel restriction site for the enzyme that cuts the original amplified PCR product of $494 \mathrm{bp}$ into two fragments of 179 and $315 \mathrm{bp}$. The appearance of the two bands indicates homozygosity for the mutation and the three bands heterozygosity. M-molecular weight marker X of Boehringer (Germany). 
(T294fs25X) in two families with congenital absence of AFP. The nonsense-mediated mRNA decay pathway by RNA surveillance $^{12}$ is well known for degrading mRNA encoding premature termination codons. Moreover, it was recently demonstrated that premature termination of translation, resulting from frameshift mutations occurring in exons that are followed by introns, causes efficient degradation of the mRNA by this pathway, thus resulting in less severe phenotypes then truncating mutations occurring in the last exon, where the mRNA is not degraded. ${ }^{13}$ The frameshift in the internal eighth exon we observed would thus be expected to cause the degradation of the mutated mRNA. However, we could not directly test the stability of the mutant AFP mRNA since lymphoblastoid lines, the only available patients' tissue, do not express AFP in controls (not shown). The very low levels of AFP detected by immunological methods in the serum and in the placenta of the patients described ${ }^{11}$ could be caused by the crossreactivity of the antibodies that were used. Analysis of all available family members revealed that none of the homozygotes and heterozygotes shows abnormalities, moreover, the father in family A proved to be homozygous (Figure 1).

The alpha-fetoprotein gene $(A f p)$ is a member of a multigenic family that comprises the related genes encoding albumin, alpha-albumin, and vitamin D-binding protein. These genes are clustered within a $1.1 \mathrm{Mb}$ interval on chromosome 4q11-13 in humans, ${ }^{14}$ a $114 \mathrm{~kb}$ interval on chromosome 5 in the mouse, ${ }^{14}$ and a $92 \mathrm{~kb}$ interval on chromosome 14 in the rat. ${ }^{14}$ This conserved organization has been proposed to be important for the developmental expression switch of the genes of the family after birth. ${ }^{15} \mathrm{~A}$ $10^{4}$-fold diminishing level of AFP and increase in albumin blood levels occur at the end of the embryonic period of development. The switch is carried out at the transcriptional level. ${ }^{6}$ Only in pathological state in adult life (eg, hepatic tumor or germ-cell tumor) AFP levels rise ${ }^{5}$ and a decrease in albumin synthesis is observed. ${ }^{16}$ Several hypotheses have been proposed for the physiological function of AFP. ${ }^{17-19}$ AFP, like albumin, is also able to bind steroids as well as endogenous and exogenous substances such as fatty acids, bilirubin, and various pharmaceutical agents, suggesting that AFP may play a general transportation role. ${ }^{20}$ The region shown to bind estradiol and to have antiestrotrophic activity is located between amino acids 472 and $479 ;^{21,22}$ this activity would thus be missing in our patients even if the truncated protein is produced. AFP has also been proposed to be one protein that protects the embryo against the maternal immune system. ${ }^{23,24}$ Deficiency in this function may be observed by the pregnancy complications and placenta abnormalities revealed in our patients. ${ }^{11}$

Owing to its high level of expression during embryonic development, AFP has been assumed to be essential for mammalian development. This study demonstrates that
AFP is not necessary for the completion of pregnancy and birth of healthy babies. In agreement with our observation, it was recently shown, using gene targeting in mice, that AFP is not essential for pregnancy to develop. Neither the embryos nor the maternal environment are AFP-dependent in order to produce a normal offspring. However, whereas mutant homozygous adult males were viable and fertile, as we also observed for the mutation-homozygous father in pedigree A, AFP-null females mice were infertile by a dysfunction of the hypothalamic/pituitary system, leading to anovulation. ${ }^{25}$ Although we did not get an infertility history from the affected families, the homozygous females have not yet reached fertility age and will need to be evaluated thoroughly.

Although congenital deficiency of AFP is a very rare observation, this finding should be considered in patients who are followed by monitoring their AFP, for example, hepatocellular carcinoma and teratoma. We suggest measuring their basal levels as an indication for their ability to produce and to be followed by AFP.

\section{Acknowledgements}

We thank the members of the families for their cooperation in this study. We also thank Professor Rivka Carmi for a critical review of the manuscript, and the anonymous reviewers for their valuable suggestions. This project was sponsored in part by the Helen Tennen fund.

\section{Electronic database}

GenBank,http://www.ncbi.nlm.nih.gov/entrez/query.fcgi?db = PubMed (for human AFP mRNA NM_001134, for human AFP gene cluster NT_006216, for mouse AFP gene cluster NT_039308, for rat AFP gene cluster NW_047424).

\section{References}

1 Bergstrand CG, Czar B: Demonstration of a new protein fraction in serum from the human fetus. Scand J Clin Lab Invest 1956; 8: 174.

2 Leighton PC, Kitau MJ, Chard T, Gordon YB, Leek AE: Levels of alpha-fetoprotein in maternal blood as a screening test for fetal neural-tube defect. Lancet 1975; 7943: 1012-1015.

3 Cuckle HS, Wald NJ, Lindenbaum RH: Maternal serum alphafetoprotein measurement: a screening test for Down syndrome. Lancet 1984; 1: 926-929.

4 Sher C, Shohat M: Congenital deficiency of AFP and Down syndrome screening. Prenat Diagn 1997; 17: 884-885.

5 Gitlin D: Normal biology of AFP Part I Biology of alpha fetoprotein. Ann N Y Acad Sci 1975; 259: 7-16.

6 Tilghman SM, Belayew A: Transcriptional control of the murine albumin/alpha-fetoprotein locus during development. Proc Natl Acad Sci USA 1982; 79: 5254-5257.

7 McVey JH, Michaelides K, Hansen LP et al: A G->A substitution in an HNF I binding site in the human alpha-fetoprotein gene is associated with hereditary persistence of alpha-fetoprotein (HPAFP). Hum Mol Genet 1993; 2: 379-384.

8 Blesa JR, Giner-Duran R, Vidal J et al: Report of hereditary persistence of alpha-fetoprotein in a Spanish family: molecular basis and clinical concerns. J Hepatol 2003; 38: 541-544. 
9 Alj Y, Georgiakaki M, Savouret JF et al: Hereditary persistence of alpha-fetoprotein is due to both proximal and distal hepatocyte nuclear factor-1 site mutations. Gastroenterology 2004; 126: 308-317.

10 Greenberg F, Faucett A, Rose E et al: Congenital deficiency of AFP. Am J Obstet Gynecol 1992; 167: 509-511.

11 Sharony R, Amiel A, Bouaron N, Kidron D, Itzhaky D, Fejgin M: Congenital deficiency of alpha fetoprotein and associated chromosomal abnormality in the placenta. Am J Med Genet 2003; 121A: 113-117.

12 Maquat LE: Nonsense-mediated mRNA decay:splicing, translation and mRNP dynamics. Nat Rev Mol Cell Biol 2004; 5: 89-99.

13 Inoue $\mathrm{K}$, Khajavi $\mathrm{M}$, Ohyama $\mathrm{T}$ et al: Molecular mechanism for distinct neurological phenotypes conveyed by allelic truncating mutations. Nat Genet 2004; 36: 361-369.

14 http://www.ncbi.nlm.nih.gov/entrez/query.fcgi?db = PubMed for human: NT_006216, for mouse: NT_039308, for rat: NW_047424.

15 Camper SA, Tilghman SM: Postnatal repression of the alphafetoprotein gene is enhancer independent. Genes Dev 1989; 3: $537-546$.

16 Lazarevich NL: Molecular mechanism of alpha-fetopeotein gene expression. Biochemistry (Moscow) 2000; 65: 117-133.

17 Chen H, Egan JO, Chiu J-F: Regulation and activities of alphafetoprotein. Crit Rev Eukaryot Gene Expression 1997; 7: 11-41.
18 Deutsch HF: Chemistry and biology of alpha-fetoprotein. $A d v$ Cancer Res 1991; 56: 253-312.

19 Abelev GI, Eraiser TL: Cellular aspects of alpha-fetoprotein reexpression in tumors. Semin Cancer Biol 1999; 9: 95-107.

20 Gillespie JR, Uversky VN: Structure and function of alphafetoprotein: a biophysical overview. Biochim Biophys Acta 2000; 1480: 41-56.

21 Vakharia D, Mizejewski GJ: Human alpha-fetoprotein peptides bind estrogen receptor and estradiol, and suppress breast cancer. Breast Cancer Res Treat. 2000; 63: 41-52.

22 Mesfin FB, Bennett JA, Jacobson HI, Zhu S, Andersen TT: Alphafetoprotein-derived antiestrotrophic octapeptide. Biochim Biophys Acta 2000; 1501: 33-43

23 Tomasi TB: Structure and function of alpha-fetoprotein. Annu Rev Med 1977; 28: 453-465.

24 Yamashita T, Nakane A, Watanabe T, Miyoshi I, Kasai N: Evidence that alpha-fetoprotein suppresses the immunological function in transgenic mice. Biochem Biophys Res Commun. 1994; 201: $1154-1159$

25 Gabant P, Forrester L, Nichols J et al: Alpha-fetoprotein, the major fetal serum protein, is not essential for embryonic development but is required for female fertility. Proc Natl Acad Sci USA 2002; 99: $12865-12870$. 